\title{
Skin Temperature and Exercise Performance after Passive Rest in a Cool Environment ${ }^{+}$
}

\author{
Areti Kapnia ${ }^{1, *}$, LydiaTsoutsoubi ${ }^{1}$, Paraskevi Gkiata ${ }^{1}$, Leonidas G. Ioannou ${ }^{1}$, \\ Yannis Koutedakis ${ }^{2,3,4}$, Vassilis Gerodimos ${ }^{5}$ and Andreas D. Flouris ${ }^{1}$ \\ 1 FAME Laboratory, School of Exercise Sciences, University of Thessaly, 42100 Trikala, Greece \\ 2 Human Performance Group, CREHP, DPESS, University of Thessaly, 42100 Trikala, Greece \\ 3 Institute for Research and Technology Thessaly-CERTH, 42100 Trikala, Greece \\ 4 Department of Clinical and Laboratory Research, Medical School, University of Thessaly, \\ 41500 Larisa, Greece \\ 5 School of Physical Education and Exercise Science, University of Thessaly, 42100 Trikala, Greece \\ * Correspondence: areti.kapnia@gmail.com \\ + Presented at the 9th Greek Conference of Biochemistry and Physiology of Exercise, Thessaloniki, Greece, \\ 18-20 October 2019.
}

Published: 30 August 2019

\begin{abstract}
Aim: Warm-up activates muscular thermogenesis leading to enhanced athletic performance and reduced risk for exercise-induced injuries. However, very little is known about the thermo physiological responses of elite basketball players during the time spent on bench $(\mathrm{BENCH})$ and consequently its impact on athletic performance in cool environments. Therefore, the purpose of this study was to investigate the impact of $\mathrm{BENCH}$ on the thermo physiological responses and athletic performance of elite basketball players. Material \& Method: Six elite male basketball players (age, $24.9 \pm 4.6$ year; BMI, $25.5 \pm 1.8 \mathrm{~kg} / \mathrm{m}^{2}$ ) participated in the study. Following a 20-min warm up, the participants were randomly allocated in four different scenarios: (i) 9-min BENCH wearing basketball uniform, (ii) 9-min BENCH wearing basketball uniform and insulative clothing, (iii) 23-min BENCH wearing basketball uniform, and (iv) 23-min BENCH wearing basketball uniform and insulative clothing. The athletic performance of the participants was examined by conducting fitness test pre- and post-BENCH scenarios. Mean skin temperature ( $\left.\mathrm{T}_{\mathrm{sk}}\right)$ was calculated from two sites (arm and thigh), while ambient temperature was recorded using a portable weather station. Results: Ambient temperature $\left(16.8 \pm 1.2^{\circ} \mathrm{C}\right)$ ranged from 18.2 to $15.5^{\circ} \mathrm{C}$. We identified an increase of $1{ }^{\circ} \mathrm{C}$ in Tsk during 23-min BENCH scenarios $(p<0.05)$. Similarly, we found that counter-movement jump was significantly reduced after 23-min BENCH with basketball uniform $(-2.8 \mathrm{~cm})$ and 23-min BENCH with basketball uniform and insulative clothing $(-3.4 \mathrm{~cm}, p$ $<0.05)$. On the other hand, there were no statistically significant differences in $T_{s k}$ and athletic performance between the baseline and post 9-min BENCH measures $(p>0.05)$. Conclusions: The present study showed that $23 \mathrm{~min}$ of bench time reduces high-intensity players' performance in both conditions ( $23 \mathrm{~min}$ bench time + basketball uniform, 23 min bench time + basketball uniform and insulative clothing) in cool environment. Thus, further studies are needed in order to identify factors causing impaired performance.
\end{abstract}

Keywords: cool environment; exercise performance; passive rest; skin temperature

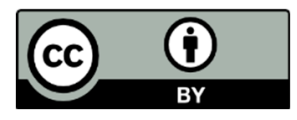

(C) 2019 by the authors. Licensee MDPI, Basel, Switzerland. This article is an open access article distributed under the terms and conditions of the Creative Commons Attribution (CC BY) license (http://creativecommons.org/licenses/by/4.0/). 